Research Article

\title{
Genetic Approach for Multiobjective Optimization of Epicyclical Gear Train
}

\author{
Kaoutar Daoudi (D), El Mosthapha Boudi, and Mohsine Abdellah \\ Energetic Team, Mechanical and Industrial Systems (EMISys), Mohammadia School of Engineers, \\ Mohammed V-University in Rabat, Rabat BP 765, Morocco \\ Correspondence should be addressed to Kaoutar Daoudi; kaoutardaoudi@research.emi.ac.ma
}

Received 8 July 2019; Revised 23 September 2019; Accepted 9 October 2019; Published 4 November 2019

Academic Editor: Kauko Leiviskä

Copyright ( ) 2019 Kaoutar Daoudi et al. This is an open access article distributed under the Creative Commons Attribution License, which permits unrestricted use, distribution, and reproduction in any medium, provided the original work is properly cited.

\begin{abstract}
The determination of optimal design of the planetary gear train with a lightweight, a short center distance, and a high efficiency is an important issue in the preliminary design of power transmission systems. Conventional and traditional methods have been widely used in optimization. They are deterministic and limited to solve some mechanical problems with several variables and constraints. Therefore, some optimization methods have been developed, such as the nonconventional method, the genetic algorithm (GA). This paper describes a multiobjective optimization for the epicyclical gear train system using the GA. It is aimed to obtain the optimal dimensions for epicyclical gear components like a module, number of teeth, the tooth width, the shaft diameter of the gears, and a performed efficiency under the variation of operating mode of PGT system. The problem is formulated under the satisfaction of assembly and balance constraints, bending strength, contact strength of teeth, and other dimension conditions. The mathematical model and all steps of the GA are presented in detail.
\end{abstract}

\section{Introduction}

Gear trains are used in most types of machinery and vehicles for power transmission. Epicyclical gear train takes a very significant place among the gear transmissions which are used in many branches of industry such as automobile, aerospace, machine tools, and turbines. It has several advantages like a smaller envelope size than a parallel shaft for the same power, low weight, coaxial shafts resulting in more compact installation, and high transmission ratio speed and efficiency [1].

The design of the planetary gear train is highly complicated and specific. This complexity leads to many design variables, mathematical formulations, constraints, and many influencing factors. Using conventional or traditional optimization techniques to solve a design problem, they could not provide an optimum result according to the complex shape and geometry of gears and many factors. Therefore, a stochastic approach genetic algorithm (GA) is applied to solve this problem and to obtain a satisfactory result as well
$[2,3]$. Therefore, many approaches for planetary gear optimization, especially a minimal weight or volume and a performed efficiency, have been proposed in the literature.

Yan and Lai [4] hssave described a concept of elementary gear trains, which has been developed to solve the conjugate surface equations. This concept shows the solid modeling of the proposed elementary planetary gear trains. Rao [5] has used the principles of the genetic process to test isomorphism as well as to know relatively the characteristics of speed ratios and transmission efficiency, with the same number of links and degrees of freedom. Mundo [6] has studied the model of the planetary gear train with noncircular gear geometries by illustrating the example of a bicycle where the efforts of pedaling have been minimized. Rosic et al. [7] have described the genetic algorithm applied to a multiobjective optimization of a planetary gear train, especially the efficiency and the axial distance. However, this approach gives a quantitative description of the compromise between efficiency and size. Stefanovic and Milovancevic [8] have presented an original model for multicriteria 
optimization of the planetary gear trains. A mathematical model for optimization is defined by the variables, objective functions, and conditions required for the proper functioning of a system. Volume, mass, efficiency, and production costs describe the objective function. Chen et al. [9] used a differential evolution algorithm to optimize a twostage planetary gear train. They have proved an optimum design of the planetary gear train with minimum volume and weight. Höhn et al. [10] presented a study on lightweight design of planetary gear transmission. To achieve their objective, different normal modules are used for each transmission stage which is also the best way to reduce the tooth-load factors or to increase efficiency. Dilawer et al. [11] described an optimal design of the compound of the epicyclic gear train with the load analysis which was carried out in the gear trains by different modules and power levels. In the study of Akhila and Reddy [12], the main aim was to design and analyze a three-stage epicyclical planetary reduction gear unit used for a flight vehicle. Daoudi and Boudi [13] have proposed a methodology for the shape optimization of the epicyclical gear train system based on parametric shape optimization. Their objective was to design a lighter gearbox with respect to kinematic and dynamic behavior. Harsha and Rao [14] used the genetic algorithm to optimize the volume function of two stages of the planetary gear train. The variables were tooth number of the sun gear, module, tooth width, and modification coefficient of the sun gear for each stage. The software MATLAB is used with the satisfaction of the strength and geometric constraints to give results. Mei et al. [15] adopted the genetic algorithm in the entire process for the purpose of reducing the variation of transmission errors in the meshing process by the modification of the tooth profile of spur gear. Hüseyin Filiz et al. [16] applied the GA for the minimization of kinetic energy. Allowable bending stress and allowable contact stress are considered as design constraints. Minimum teeth number for a given pressure angle, center distance, recommendation on the face width, and limitations on teeth ratios are considered as geometrical and kinematical constraints. Kissling and Bae [17] have described a new optimization tool, based on KISSsys software, which permits to layout automatically a complete gearbox using functions for the layout of gear stages, shaft dimensions and bearings, lifetime, safety factors, and the total ratio. This tool is used to generate a complete set of different variants of gear reducers. The main results are displayed in 3D graphics, showing weight, costs, and efficiency of the different variants. Adarsh Kumar et al. [18] presented several optimization techniques of epicyclic gear train to reduce load failures in design improvement and optimization of the products. Daoudi and Boudi [19] have illustrated a comparison between two advanced optimization algorithms known as genetic algorithm (GA) and particle swarm optimization (PSO) in order to find the optimal combination of design parameters for minimum volume of planetary gear train. They have presented another work about the minimization of the weight and the center distance of one pair of spur gears [20]. Nandeppagoudar et al. [21] redesigned the three stages of planetary gearbox by reducing one stage which will be suitable for machine tool application where the space and load constrains is the prime objectives. Analytical and numerical results are compared to see the effectiveness of modified planetary gearbox.

The objective of this study stems from the idea of providing an optimal design of the epicyclical gear train by the genetic algorithm approach. It would offer a global optimization of the geometrical parameters of the epicyclical gear train system as a module, number of teeth, tooth width, and shaft diameter, in order to obtain light weight, short center distance, and maximal efficiency. In addition, the specificity of the present work is that it takes into account the variation of the gear ratio or the operating modes of the PGT.

\section{Genetic Algorithm}

Originally developed by Holland, the genetic algorithm (GA) is a robust technique based on the natural selection and genetic production mechanism. This algorithm works with a group of possible solutions within a search space instead of a single solution, as described in gradient optimization methods $[22,23]$.

Genetic algorithm is referred to as a search method of the optimal solution to simulate Darwin's genetic selection and biological evolution process. In fact, it is a series of random iterations and evolutionary computations which simulate the process of selection, crossover, and mutation occurred in natural selection and population genetic as described in Figure 1. The good quality of the solution is gradually maintained and combined according to the survival of the fittest and through crossover and mutation, while continually producing better individuals and out of bad individuals $[2,24]$. Through the generational produce and optimizing the individual, the whole group evolves forward and constantly approaches to the optimal solution.

\section{Problem Definition}

The model of the application was a single stage of an epicyclical gear train type I with three planets as shown in Figure 2. The objective of this work has been the minimization of the weight, the center distance, and the maximization of the efficiency.

Many factors and parameters like torque, material, tooth width, input speed, module, and others have been applied to design optimization as described in Table 1. The product of the transversal load factors and the application factors for bending stress and contact stress has been considered to be equal to 1 just to simplify the calculation.

3.1. Objective Function. The objective function is a quantity to be minimized or maximized by exploring a search space under the imposed constraints. In this paper, three objective functions have been defined as follows:

(1) $F_{1}\left(b, m, Z_{\mathrm{s}}, Z_{\mathrm{p}}, d_{\mathrm{s}}^{\prime}, d_{\mathrm{p}}^{\prime}\right)$ : minimization of the weight

(2) $F_{2}\left(m, Z_{\mathrm{s}}, Z_{\mathrm{p}}\right)$ : minimisation of the center distance

(3) $F_{3}\left(\eta_{\mathrm{PGT}}\right)$ : maximization of efficiency 


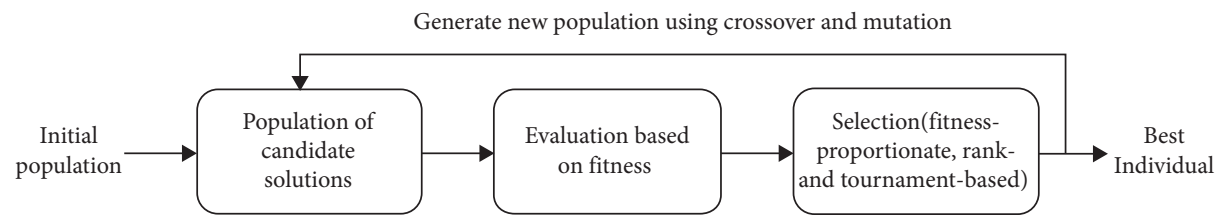

Figure 1: Flowchart of GA for solving the problem.

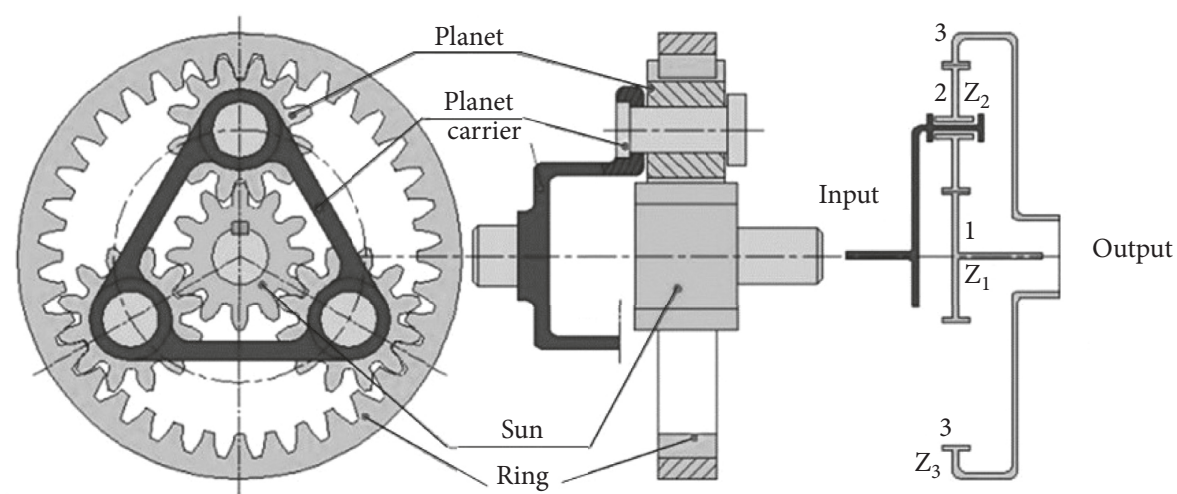

Figure 2: Simple epicyclical gear drive type I [1].

TABle 1: Description of parameters and variables [25, 26].

\begin{tabular}{|c|c|c|}
\hline Parameters & Symbol & Coefficient value \\
\hline Tooth width & $b$ & {$\left[\begin{array}{ll}12 & 120\end{array}\right]$} \\
\hline Module & $m$ & {$\left[\begin{array}{ll}2 & 20\end{array}\right]$} \\
\hline Tooth number of sun gear & $Z_{\mathrm{s}}$ & {$\left[\begin{array}{ll}17 & 30\end{array}\right]$} \\
\hline Tooth number of planet gear & $Z_{\mathrm{p}}$ & {$\left[\begin{array}{ll}17 & 50\end{array}\right]$} \\
\hline Diameter of sun shaft & $d_{s}^{\prime}$ & {$\left[\begin{array}{ll}10 & 30\end{array}\right]$} \\
\hline Diameter of planet shaft & $d_{\mathrm{p}}^{\prime}$ & {$[10$ 40] } \\
\hline Input power & $\stackrel{P}{P}$ & 7.5 \\
\hline Input speed & $n$ & 1500 \\
\hline Density material of standard steel & $\rho$ & 7850 \\
\hline Helix angle factor & $Z_{\beta}$ & 1 \\
\hline Elastic coefficient & $Z_{\mathrm{E}}$ & 189.98 \\
\hline Contact ratio coefficient & $Z_{\varepsilon}$ & 0.94 \\
\hline Product of load factor & $K_{i}$ & 1.75 \\
\hline Tooth form factor & $Y_{\mathrm{Fa}}$ & 2 \\
\hline Stress concentration coefficient & $Y_{\mathrm{Sa}}$ & 1.73 \\
\hline Contact ratio coefficient & $Y_{\varepsilon}$ & 1.08 \\
\hline Allowable contact stress & {$\left[\sigma_{\mathcal{C}_{\mathfrak{j} m}}\right]$} & 1100 \\
\hline Allowable bending stress & {$\left[\sigma_{\mathrm{b}_{\mathrm{adm}}}^{\mathrm{adm}}\right]$} & 460 \\
\hline Allowable shearing stress of shafts & $\gamma$ & 30.67 \\
\hline
\end{tabular}

The total weight of the planetary gear train has been presented by the envelope of the three components: sun gear, planet gear, and ring gear. For the number of teeth, just the number of teeth of the sun and the planet will be considered as variables. The number of teeth $Z_{\mathrm{r}}$ is generated by the linear equation of $Z_{s}$ and $Z_{p}$, equation (13). Equation (1) defines the expression of the weight function:

$$
F_{1}=\frac{\pi}{4} \rho \cdot b\left[d_{\mathrm{s}}^{2}+n_{\mathrm{p}} \cdot d_{\mathrm{p}}^{2}+d_{\mathrm{r}}^{2}-\left(d_{\mathrm{s}}^{\prime}+n_{p} \cdot d_{p}^{\prime 2}\right)\right] ; \quad d=m \cdot Z .
$$

The minimization of the center distance determines smaller gears which would require less material and cost to make and less space to operate it. The following equation presents the center distance of the epicyclical gear train system [27]:

$$
F_{2}=\frac{m}{2}\left(Z_{\mathrm{s}}+Z_{\mathrm{p}}\right)
$$

The last objective function is the efficiency, which is more detailed in the part bellow and defined as follows:

$$
F_{3}=\eta_{\mathrm{PGT}}
$$

3.2. Constraint Functions. This optimization has been formulated with the satisfaction of many constraints. The bending strength, the contact strength, and the dynamic factor $K_{\mathrm{V}}$ were calculated according to method $\mathrm{B}$ of the standard ISO [28].

(i) Dimensional constraint:

$$
\text { number of teeth: } Z_{\mathrm{s}} \geq Z_{\mathrm{p}} \text {, }
$$

width coefficient of tooth: $6<k \leq 12 ; b=m \cdot k$. 
(ii) Balance and assembly condition for PGT:

$$
\begin{aligned}
\frac{Z_{\mathrm{p}}+Z_{\mathrm{s}}}{n_{\mathrm{p}}} & =\text { integer number, } \\
Z_{\mathrm{p}}+2<\left(Z_{\mathrm{p}}+Z_{\mathrm{s}}\right) \times \sin \left(\frac{180}{n_{\mathrm{p}}}\right) & \\
Z_{\mathrm{r}} & =2 \times Z_{\mathrm{p}}+Z_{\mathrm{s}} \\
a & =\frac{\left(d_{\mathrm{s}}+d_{\mathrm{p}}\right)}{2}=\frac{\left(d_{\mathrm{r}}-d_{\mathrm{p}}\right)}{2} .
\end{aligned}
$$

(iii) Bending strength of teeth:

$$
\sigma_{\mathrm{b}}=Y_{\mathrm{Fa}} Y_{\mathrm{Sa}} Y_{\varepsilon} \frac{2 K T}{b Z m^{2}} K_{\mathrm{A}} K_{\mathrm{V}} K_{\mathrm{F} \alpha} K_{\mathrm{F} \beta} \leq\left[\sigma_{\mathrm{b}_{\mathrm{adm}}}\right]
$$

(iv) Contact strength of teeth: The expression of the contact stress in equation (7) represents the wear load of gears between planet and sun gears and between planet and ring gears:

$$
\sigma_{\mathrm{c}}=Z_{\beta} Z_{\mathrm{H}} Z_{\mathrm{E}} Z_{\varepsilon} \sqrt{\frac{2 T\left(I_{\mathrm{pgt}} \pm 1\right)}{b Z^{2} m^{2} I_{\mathrm{pgt}}}} K_{\mathrm{A}} K_{\mathrm{V}} K_{\mathrm{H} \alpha} K_{\mathrm{H} \beta} \leq\left[\sigma_{c_{\mathrm{adm}}}\right] .
$$

The condition of shaft diameters is defined in equation (8). The planet shaft is considered the most solicited in this study to simplify the calculation:

$$
d_{\mathrm{p}}^{\prime 3} \geq \frac{4.97 e 6 \cdot P}{n^{\prime} \cdot v}, \quad n^{\prime}=\frac{n}{a}
$$

Therefore, the previous expression shows that eight constraints must be introduced in the objective functions. The syntax of the constraints in the genetic algorithm has been presented by the function $g_{i}(x)$, where $i$ presents the number of all constraints; in our case, $i=1, \ldots, 8$. The symbol $x$ presents the variable vector. A feasible design must satisfy all constraints where all $g_{i}(x)$ function values must be less than or equal to zero. All constraints considered in the above problem are inequal, except for the last one. Then, the constraints can be reformulated as shown in the following equations:

$$
\begin{aligned}
& g_{1}(x)=6-\frac{b}{m}, \\
& g_{2}(x)=\frac{b}{m}-12 \\
& g_{3}(x)=Z_{\mathrm{p}}+2-\left(Z_{\mathrm{p}}+Z_{\mathrm{s}}\right) \times \sin \left(\frac{180}{n_{\mathrm{p}}}\right), \\
& g_{4}(x)=Y_{\mathrm{Fa}} Y_{\mathrm{Sa}} Y_{\varepsilon} \frac{2 K T}{b Z m^{2}} K_{\mathrm{A}} K_{\mathrm{V}} K_{\mathrm{F} \alpha} K_{\mathrm{F} \beta}-\left[\sigma_{\mathrm{b}_{\mathrm{adm}}}\right],
\end{aligned}
$$

$$
\begin{aligned}
& g_{5}(x)=Z_{\beta} Z_{\mathrm{H}} Z_{\mathrm{E}} Z_{\varepsilon} \sqrt{\frac{2 T(i \pm 1)}{b Z^{2} m^{2} i}} K_{\mathrm{A}} K_{\mathrm{V}} K_{\mathrm{H} \alpha} K_{\mathrm{H} \beta}-\left[\sigma_{\mathrm{c}_{\mathrm{adm}}}\right] \\
& g_{6}(x)=\frac{4.97 e 6 \cdot P}{n^{\prime} \cdot v}-d_{p}^{\prime 3} \\
& g_{7}(x)=\frac{Z_{\mathrm{p}}+Z_{\mathrm{s}}}{n_{\mathrm{p}}}-\text { integer number } \\
& g_{8}(x)=Z_{\mathrm{p}}-Z_{\mathrm{s}}
\end{aligned}
$$

3.3. Binary Coding in GA. Amount of iterations and variables in a function are coded in bit patterns as shown in Table 2. Generally, binary-coded chromosomes having l's and 0's were used. Genetic operators could be used due to this coding using the following formula [22]:

$$
2^{l} \geq \frac{x(i)_{\max }-x(i)_{\min }}{\varepsilon}+1 \text {. }
$$

Here, $l$ represents the string length for all variables, $x(i)_{\min }$ and $x(i)_{\max }$ represents respectively lower and upper boundary of variable, and $\varepsilon$ is the variable step. When all string lengths of each variable are determined, the chromosome is produced by the concatenation of the previous as defined in Table 2.

3.4. Efficiency Analysis. The planetary gear train is a system with one configuration and many combinations. Indeed, it can have the case where at least one of the parts, planetary, ring, or the planet carrier, is fixed and the two others are either the input or the output. In this case, there are six different operating modes or transmission ratios and a different expression of transmission efficiency [29, 30]. Figure 3 presents the basic circuit of the transmission relation diagram of the simple planetary gear train (SPGT) with $1 \mathrm{DOF}$, where $i, j$, and $k$ represent, respectively, the sun, ring, and planet carrier, and the fixed sign indicates which part of PGT was blocked [31, 32].

The transmission relation diagram of SPGT with one degree of freedom (1 DOF) has six basic cases, and their efficiency expression is given in Table 3. Equation (18) describes the basic meshing efficiency between the driver and the driven gears. It is used in the contact ratio range $1<\varepsilon_{\alpha}<2, \mu$ presents the friction coefficient with a constant value of 0.05 and $Z_{i}$ is the teeth number of the gear $i$ and $j$, respectively. In this paper, the value of the basic transmission coefficient has been $\eta_{\mathrm{PGT}}^{0}=0.95$ [33]:

$$
\eta_{\mathrm{PGT}}^{0}=1-\pi \cdot \mu\left(\frac{1}{Z_{j}} \pm \frac{1}{Z_{i}}\right) \cdot\left(\varepsilon_{1}^{2}+\varepsilon_{2}^{2}-\varepsilon_{1}-\varepsilon_{2}+1\right) \text {. }
$$

Based on the kinematic equation of the gear system, the Willis formula, the torque equation, and the power balance equation have been obtained, as expressed in equations (19)-(21) [34]: 
TABLE 2: Coding of variables.

\begin{tabular}{lccc}
\hline Design variable vectors & Vectors & Randomized binary digits & String length \\
\hline Tooth width $(\varepsilon=0.01)$ & $\mathrm{X}(1)$ & 111110101 & 1011011 \\
Module $(\varepsilon=0.1)$ & $\mathrm{X}(2)$ & 1101 & 7 \\
Number of teeth_sun $(\varepsilon=1)$ & $\mathrm{X}(3)$ & 101011 & 4 \\
Number of teeth_planets $(\varepsilon=1)$ & $\mathrm{X}(4)$ & 11111 & 6 \\
Shaft diameter_sun $(\varepsilon=1)$ & $\mathrm{X}(5)$ & 1110100 & 5 \\
Shaft diameter_planet $(\varepsilon=1)$ & $\mathrm{X}(6)$ & 11111010110110111101101011111111110100 & 7 \\
A single chromosome & & 38 \\
\hline
\end{tabular}

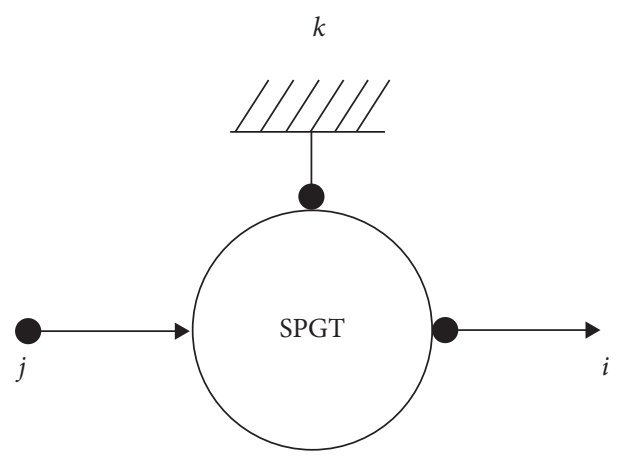

FIgURE 3: Basic circuit transmission relation diagram.

$$
\omega_{i}-\tau \cdot \omega_{j}+(\tau-1) \cdot \omega_{k}=0 ; \quad \tau= \pm \frac{Z_{j}}{Z_{i}},
$$

where $\tau$ represents the basic gear ratio between $j$ and $i$ gear and the $\mp$ sign represents the internal and external gear pairs. As identified, $i, j$, and $k$ were $s, r$, and pc, respectively. $i=s$, $j=r$, and $k=\mathrm{pc}$, and based on the equation, the following equations were obtained:

$$
\begin{aligned}
& T_{\mathrm{s}}+T_{\mathrm{pc}}+T_{\mathrm{r}}=0, \\
& P_{\mathrm{s}}+P_{\mathrm{pc}}+P_{\mathrm{r}}=0 .
\end{aligned}
$$

Firstly, assuming the ring gear $j$ is fixed, the efficiency $\eta_{j(i-k)}$ can be calculated by using equation (22). Then, assuming the planet carrier $k$ is fixed, the efficiency $\eta_{k(i-j)}$ can be calculated by using equation (23). When assuming the sun gear $j$ is fixed, $\omega_{\mathrm{k}}$ can be obtained by formula (17) as shown in equation (24):

$$
\begin{aligned}
\eta_{j(i-k)} & =-\frac{T_{k} \cdot \omega_{k}}{T_{i} \cdot \omega_{i}}, \\
\eta_{k(i-j)} & =-\frac{T_{j} \cdot \omega_{j}}{T_{j} \cdot \omega_{j}}, \\
\omega_{k} & =\frac{1}{1-\tau} \omega_{i} .
\end{aligned}
$$

Table 2 summarizes the basic gear transmission diagram and efficiency in the six cases of the SPGT. For the complex planetary gear transmission, the equivalent efficiency $\eta_{\text {PGT }}$ is expressed in equation (25) by using equations (19), (20), and (24):

$$
\eta_{\mathrm{PGT}}=\frac{(1-\tau) \cdot \omega_{k} \cdot \eta_{j(i-k)}+\tau \cdot \omega_{j} \cdot \eta_{k(i-j)}}{\omega_{i}} .
$$

\section{Results and Discussion}

4.1. Results for Optimization of the Weight and Center Distance. Table 4 shows the best fitness of the weight and the center distance for each configuration of the epicyclical gear train, as well as the optimal design parameters for each transmission ratio variation. The first mode gives the lighter weight and the minimal center distance for the PGT system when it was a speed reducer than modes two, three, and five. However, for the case when the epicyclical gear train is used as a speed multiplier, the optimal solution has been presented at the 6 th with a value of $0.342 \mathrm{~kg}$ and 39 for the weight and the center distance, respectively.

For both operations of the PGT as speed reducer or speed multiplier, the center distance was the same $39 \mathrm{~mm}$, but for the best weight, there is a margin of a difference of $66 \mathrm{~g}$.

For the design parameters, the big size has been found in the second mode with tooth number of the sun gear of 30 and with a module of $2.75 \mathrm{~mm}$ in the 4 th mode. For the rest of the modes, the value of the tooth number of the sun and planet gears was the same with a value of 21 and 18, respectively. The shaft diameter of the sun and planet gears has been found to be equal, respectively, $20 \mathrm{~mm}$ and $17 \mathrm{~mm}$ for the first mode and $20 \mathrm{~mm}$ and $11 \mathrm{~mm}$ for the last mode.

The average of the tooth width was $26.69 \mathrm{~mm}$ in different transmission ratio, but the best one was in the first mode with a value of $24 \mathrm{~mm}$ in the case of the PGT as a speed reducer and $26 \mathrm{~mm}$ in the 6 th mode of PGT as a speed multiplier. 
TABle 3: SPGT basic gear transmission diagram and efficiency.

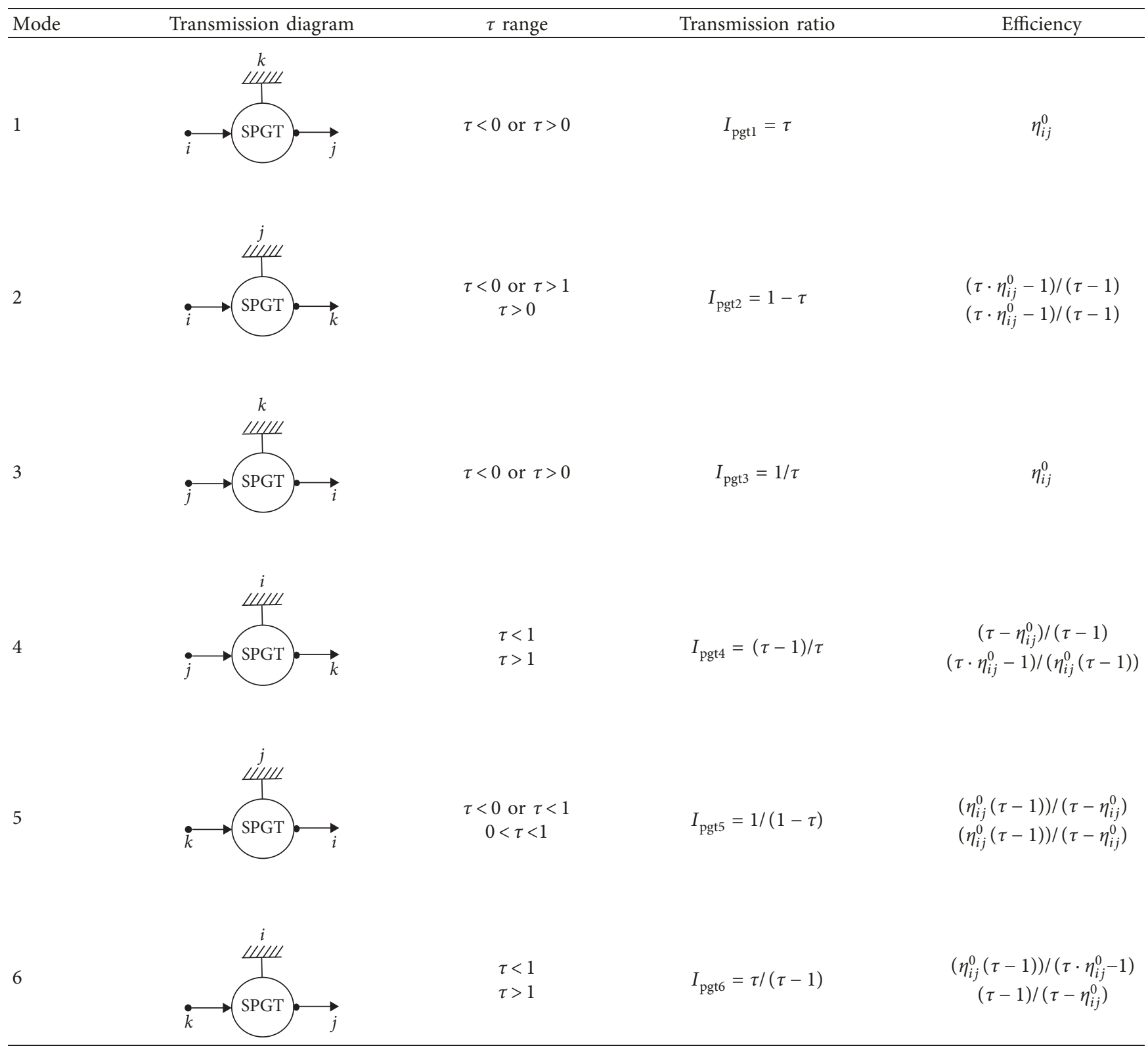

TABLE 4: Optimization results of the epicyclical gear train design.

\begin{tabular}{|c|c|c|c|c|c|c|}
\hline Function variables & Mode 1 & Mode 2 & Mode 3 & Mode 4 & Mode 5 & Mode 6 \\
\hline Number of teeth of the sun gear & 21 & 30 & 21 & 27 & 21 & 21 \\
\hline Number of teeth of the planet gear & 18 & 18 & 18 & 18 & 18 & 18 \\
\hline Number of teeth of the ring gear & 57 & 66 & 57 & 63 & 57 & 57 \\
\hline Module & 2 & 2 & 2 & 2.75 & 2 & 2 \\
\hline Shaft diameter (sun) & 20 & 30 & 18 & 18 & 23 & 20 \\
\hline Shaft diameter (planet) & 17 & 17 & 21 & 21 & 20 & 11 \\
\hline Width coefficient of tooth & 12.00 & 12.17 & 12.50 & 12.14 & 13.70 & 13.01 \\
\hline Tooth width & 24.00 & 24.33 & 25.00 & 33.38 & 27.40 & 26.03 \\
\hline Transmission ratio & -2.71 & -0.45 & 0.26 & 3.34 & 0.73 & 1.37 \\
\hline Weight of PGT & 0.276 & 0.312 & 0.280 & 0.664 & 0.375 & 0.342 \\
\hline Center distance & 39 & 39 & 39 & 61.88 & 39 & 39 \\
\hline
\end{tabular}




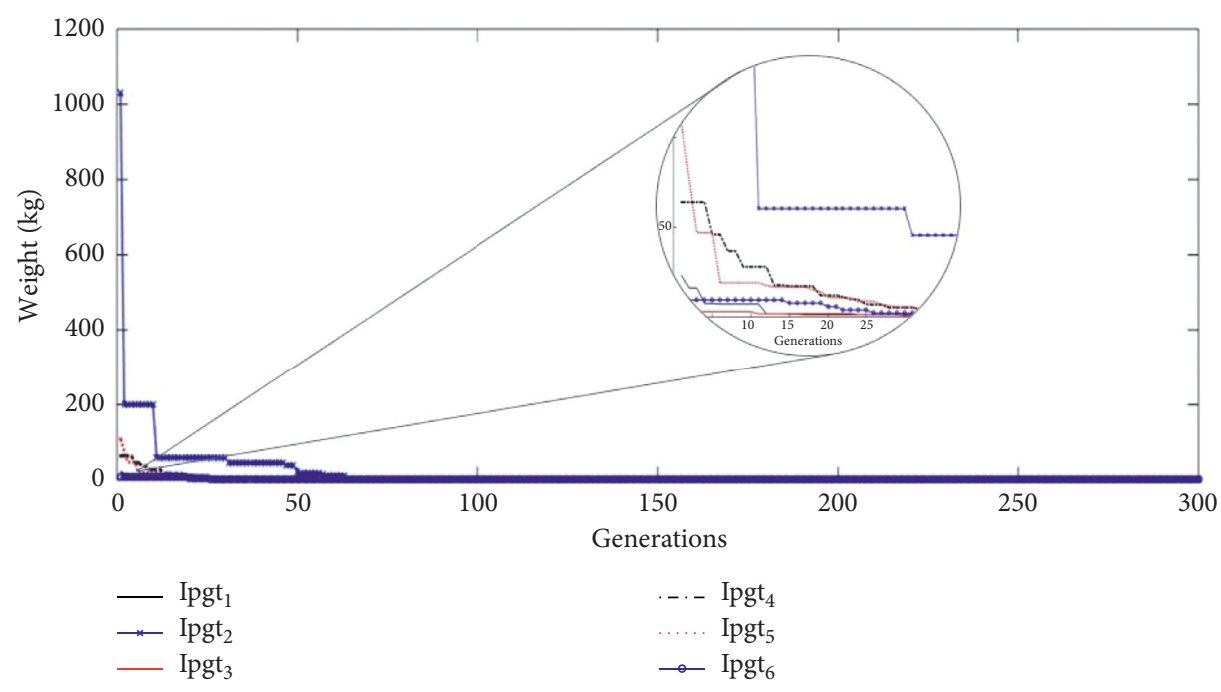

Figure 4: Variation of the optimum fitness for the weight with different transmission ratios.

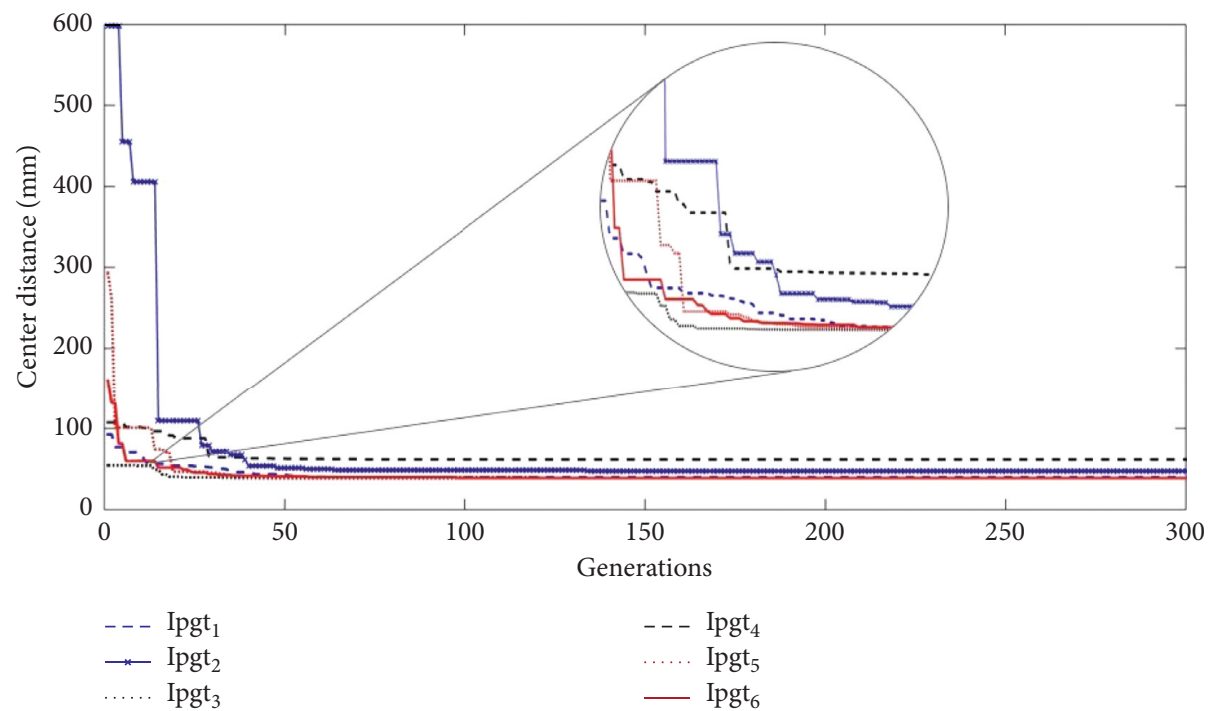

Figure 5: Best solution of the center distance in six cases of the PGT system.

The figures below show the variation of the fitness functions during generations and transmission ratio variation. The first and the third mode converge rapidly to the final solution of the minimal weight than the rest configuration of the epicyclical gear train (see Figure 4). For the center distance, mode 3 is the faster to give the final solution than the rest mode; the $2^{\text {nd }}$ mode takes more time to converge to the final solution, and it was the last for the weight and the center distance functions (see Figure 5).

A Pareto front, presented as a plot of the weight and the center distance of the planetary gear train, gives a quantitative description of the compromise between weight and size in both cases of the operation mode of the epicyclical gear train system as a speed reducer and a speed multiplier (see Figures 6 and 7).

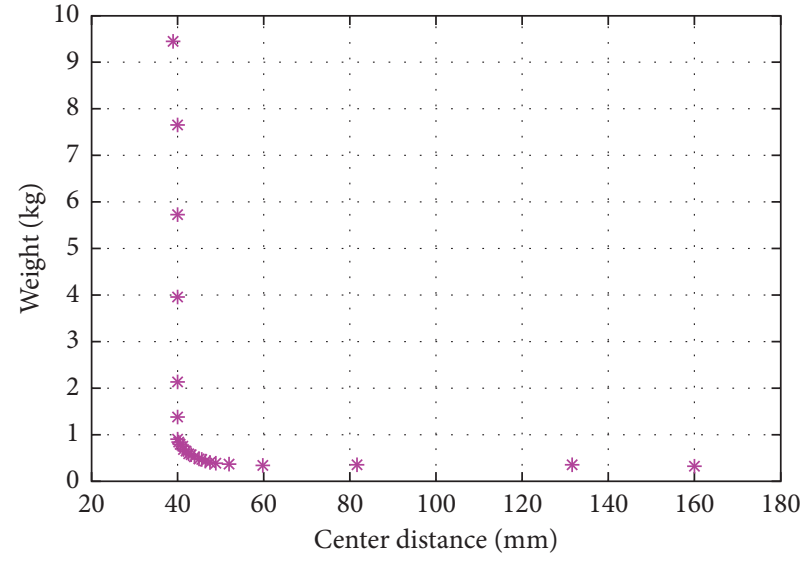

Figure 6: Pareto front of the GA multiobjective optimization of the epicyclic gear train case of a speed multiplier. 


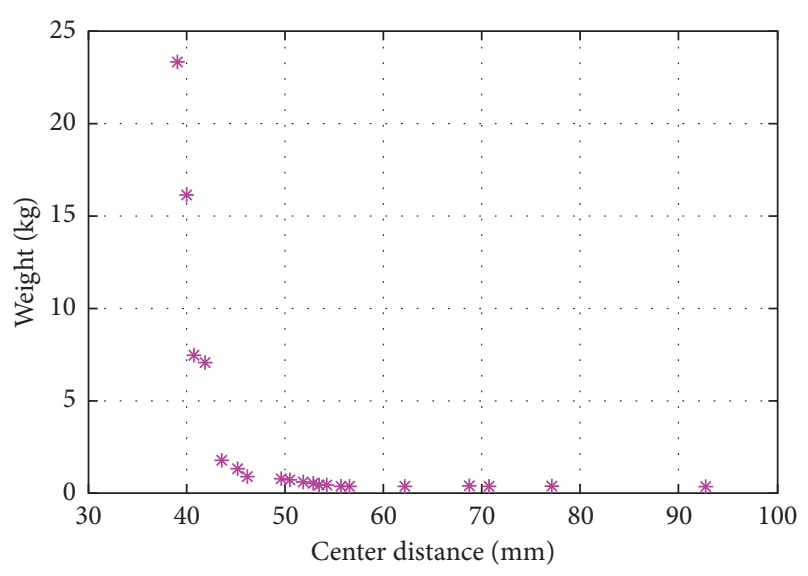

Figure 7: Pareto front of the GA multiobjective optimization of the epicyclic gear train case of a speed reducer.

TABLE 5: Optimization results of the epicyclical gear train efficiency by the GA.

\begin{tabular}{lcccccc}
\hline Types & 1 & 2 & 3 & 4 & 5 & 6 \\
\hline Range & -2.71 & -2.2 & -2.71 & -2.33 & -2.71 & -2.71 \\
Transmission ratio & -2.71 & -0.45 & 0.26 & 3.34 & 0.73 & 1.37 \\
Efficiency \% & 95.00 & 96.56 & 95.00 & 98.49 & 96.29 & 98.60 \\
\hline
\end{tabular}

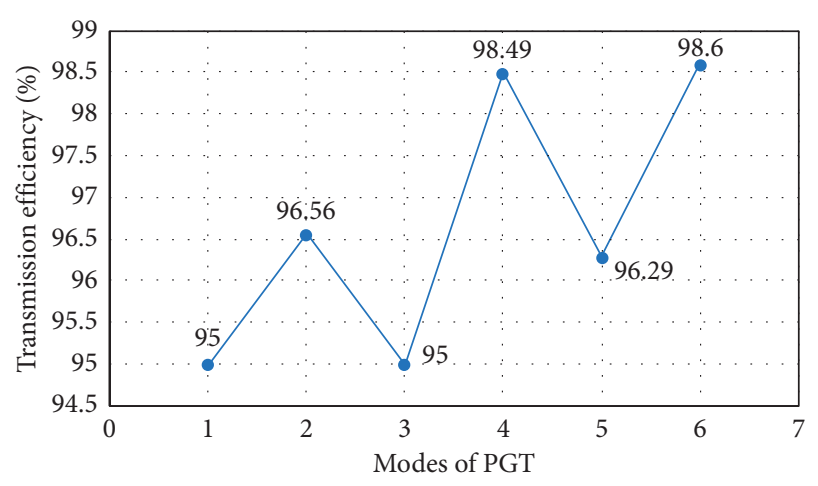

Figure 8: Optimum results for efficiency in each type of PGT.

4.2. Results for Optimization of the Efficiency. As mentioned beforehand in analysis efficiency, a planetary gear train is a system with one configuration and many combinations. Therefore, six results of the efficiency were obtained as shown in Table 5 and mapped in Figure 8. This diversity of values depends on the change of the operating mode of the epicyclical gear train. The best value of efficiency was given by the last type of PGT, the case when the ring gear was the input, the planet carrier the output, and the ring fixed, with a percentage of $98.60 \%$. However, when the sun gear was fixed and the input was the ring, the efficiency of PGT decreased by $3.60 \%$ compared to the best one.

\section{Conclusions}

Gears are the most important elements of the power transmission system. This paper presents one of the powerful metaheuristic approaches to optimization of the epicyclical gear system with the spur gear by means of the genetic algorithm. The objective of this optimization has focused on the minimization of the hall weight of the PGT, minimization of center distance, and maximization of the efficiency. The latter has been accomplished using GA under dimensional conditions of gears, balance or assembly constraint of PGT, bending strength of teeth, contact strength of teeth, and torsional strength of the gear shaft. The design variables to be optimized were the module, the number of teeth for both the sun and planet gears, the tooth width, and the shaft diameter of the gears, especially sun and planet gears.

The objective functions were analyzed according to the six cases of the PGT operation. The fitness function of the weight was found to be equal to $0.276 \mathrm{~kg}$ in mode 1 of the PGT as a speed reducer and equal to $0.342 \mathrm{~kg}$ for the $6^{\text {th }}$ mode of the PGT as a speed multiplier. The value of the center distance was $39 \mathrm{~mm}$ for two operations of the PGT as a speed reducer and a speed multiplier. The module was found to be equal to $2 \mathrm{~mm}$ in several modes. The teeth number of the sun and planet gears was found to be equal to 21 and 18 , respectively. The optimal tooth width values were found to be equal to $24.00 \mathrm{~mm}$ and $26.03 \mathrm{~mm}$ in the first and the last mode, respectively. The transmission efficiency was very important in the last type of planetary gear train system with the percentage of $98.60 \%$, the case when the planet carrier was the output, the ring the input, and the sun gear fixed.

In addition, the change of the operating mode of the epicyclical gear train system has been a great impact on the variable of optimization and in the final solutions, which is the added value of this paper compared to the previous research quoted in the literature.

In light of this study, GA is an efficient approach for the optimization of complex problems with many variables, multiobjective functions, and constraints. It also provides a better result in a short time compared with other traditional optimization.

\section{Nomenclature}

$\begin{array}{ll}a: & \begin{array}{l}\text { Center distance (mm) } \\ b:\end{array} \\ d_{\mathrm{s}}, d_{\mathrm{p}}, \text { and } d_{\mathrm{r}}: & \begin{array}{l}\text { Tooth width of gears }(\mathrm{mm}) \\ \text { Primitive diameter of sun, planet, and ring } \\ \text { gears (mm) }\end{array} \\ d_{s}^{\prime} \text { and } d_{\mathrm{p}}^{\prime}: & \begin{array}{l}\text { Shaft diameter of the sun and planet gears } \\ (\mathrm{mm})\end{array} \\ i, j, \text { and } k: & \text { The sun, the ring, and the planet carrier } \\ \mathrm{I}_{\mathrm{pgt}}: & \text { Global gear ratio PGT } \\ K: & \text { Coefficient of tooth length } \\ K_{\mathrm{A}}: & \text { Application factor } \\ K_{\mathrm{F} \alpha}: & \text { Transverse load factor (bending stress) } \\ K_{\mathrm{F} \beta}: & \text { Face load factor (bending stress) } \\ K_{\mathrm{H} \alpha}: & \text { Transverse load factor (contact stress) } \\ K_{\mathrm{H} \beta}: & \text { Face load factor (contact stress) } \\ K_{\mathrm{v}}: & \text { Dynamic factor } \\ m: & \text { Module (mm) } \\ n: & \text { Input speed (rpm) }\end{array}$




\begin{tabular}{|c|c|}
\hline$n_{\mathrm{p}}:$ & Number of planets \\
\hline$W:$ & $\begin{array}{l}\text { Total weight of the epicyclical gear train } \\
(\mathrm{kg})\end{array}$ \\
\hline$g_{i}(x):$ & Constraint functions \\
\hline $\begin{array}{l}x(i) \min \text { and } \\
x(i) \max :\end{array}$ & Lower and upper boundaries of variables \\
\hline Ps, $P$ pc and $P r:$ & $\begin{array}{l}\text { Power of sun, planet carrier, and ring gear } \\
(\mathrm{kw})\end{array}$ \\
\hline Ts, Tpc, and Tr: & $\begin{array}{l}\text { Torque of sun, planet carrier, and ring gear } \\
(\mathrm{N} \cdot \mathrm{mm})\end{array}$ \\
\hline$Z s, Z$ p, and $Z \mathrm{r}:$ & $\begin{array}{l}\text { Number of teeth on sun, planet, and ring } \\
\text { gears }\end{array}$ \\
\hline$Y_{\mathrm{Fa}}:$ & Tooth form factor \\
\hline$Y_{\mathrm{Sa}}:$ & Stress concentration coefficient \\
\hline$Y_{\varepsilon}:$ & Contact ratio coefficient \\
\hline$\omega_{i}, \omega_{j}$, and $\omega_{k}$ : & $\begin{array}{l}\text { Angular velocity of sun, planet carrier, and } \\
\operatorname{ring}\left(\mathrm{rad} \cdot \mathrm{s}^{-1}\right)\end{array}$ \\
\hline$\tau:$ & Basic transmission ratio of $\mathrm{PGT}$ \\
\hline$\rho:$ & Density material of the gear $\left(\mathrm{kg} \mathrm{m}^{-3}\right)$ \\
\hline$y:$ & Tooth form factor \\
\hline$\sigma:$ & Gear material strength $\left(\mathrm{N} \cdot \mathrm{mm}^{-2}\right)$ \\
\hline$\gamma:$ & Allowable shearing stress of shafts (Mpa) \\
\hline$\eta_{\text {PGT }}:$ & Efficiency of planetary gear train \\
\hline$\pm:$ & Internal and external gear pairs \\
\hline PGT: & Planetary gear train \\
\hline 1 DOF: & One degree of freedom \\
\hline GA: & Genetic algorithm. \\
\hline
\end{tabular}

\section{Data Availability}

The data used to support the findings of this study are available from the corresponding author upon request.

\section{Conflicts of Interest}

The authors declare that there are no conflicts of interest regarding the publication of this paper.

\section{References}

[1] K. Daoudi and E. M. Boudi, "An approach to compute the design parameters of an epicyclical gear train system," International Review on Modelling and Simulations (IREMOS), vol. 12, no. 1, p. 37, 2019.

[2] Y. Sun, Q. Xu, and J. Hu, "The theory and application of genetic algorithm," International Conference on Computer and Computing Technologies in Agriculture and Engineering, vol. 28, no. 2, p. 297, 2014.

[3] J. L. Marcelin, "Genetic optimisation of gears," The International Journal of Advanced Manufacturing Technology, vol. 17, no. 12, pp. 910-915, 2001.

[4] H.-S. Yan and T.-S. Lai, "Geometry design of an elementary planetary gear train with cylindrical tooth-profiles," Mechanism and Machine Theory, vol. 37, no. 8, pp. 757-767, 2002.

[5] A. C. Rao, "A genetic algorithm for epicyclic gear trains," Mechanism and Machine Theory, vol. 38, no. 2, pp. 135-147, 2003.

[6] D. Mundo, "Geometric design of a planetary gear train with non-circular gears," Mechanism and Machine Theory, vol. 41, no. 4, pp. 456-472, 2006.
[7] B. Rosic, S. Radenovic, L. J. Jankovic, and M. Milojevic, "Optimisation of planetary gear train using multiobjective genetic algorithm," Journal of the Balkan Tribological Association, vol. 17, no. 3, pp. 462-475, 2011.

[8] J. S.-M. and M. Milovancevic, "The optimization possibilities at the planetary gear trains," Journal of Mechanical Engineering and Automation, vol. 2, pp. 365-373, 2012.

[9] T. Chen, Z. Zhang, D. Chen, and Y. Li, "The optimization of two-stage planetary gear train based on mathmatica," Pervasive Computing and the Networked World, vol. 7719, pp. 122-136, 2013.

[10] B.-R. Höhn, K. Stahl, and P. Gwinner, "Light-weight design for planetary gear transmissions," Gear Technology, pp. 96103, 2013.

[11] S. I. Dilawer, A. Raheem Junaidi, and N. Mehdi, "Design, load analysis and optimization of compound epicyclic gear trains," American Journal of Engineering Research, vol. 2, no. 10, pp. 2320-2847, 2013.

[12] K. Akhila and A. N. R. Reddy, "Design, modelling and analysis of a 3 stage epicyclic planetary reduction gear unit of a flight vehicle," International Journal of Mechanical Engineering and Robotics Research, vol. 3, no. 4, pp. 658-666, 2014.

[13] K. Daoudi and E. M. Boudi, "Shape optimization of a planetary gear train based on the minimum weight," in Proceedings of the 2016 International Renewable and Sustainable Energy Conference (IRSEC), pp. 1021-1024, Marrakech, Morocco, November 2016.

[14] A. S. Harsha and K. M. Rao, "The optimization of two-stage planetary gear train based on Genetic Algorithm," International Journal \& Magazine of Engineering, Technology, Management and Research, vol. 4, 2017.

[15] W. Mei, J. Na, F. Yang, G. Shen, and J. Chen, "The optimal design method and standardized mathematical model of tooth profile modification of spur gear," Mathematical Problems in Engineering, vol. 2016, Article ID 6347987, 7 pages, 2016.

[16] İ. Hüseyin Filiz, S. Olguner, and E. Evyapan, "A study on optimization of planetary gear trains," Acta Physica Polonica A, vol. 132, no. 3, pp. 728-733, 2017.

[17] U. Kissling and I. Bae, "Optimization procedure for complete planetary gearboxes with torque, weight, costs and dimensional restrictions," Applied Mechanics and Materials, vol. 86, pp. 51-54, 2011.

[18] M. S. Adarsh Kumar, A. Anand, D. Kumar, and H. Yadav, "Optimization technique of epicyclic gear train and failure of gears: a review," International Journal of Research in Engineering and Technology, vol. 5, no. 3, pp. 3369-3372, 2018.

[19] K. Daoudi and E. M. Boudi, "Optimal volume design of planetary gear train using particle swarm optimization," in Proceedings of the International Conference on Optimization and Applications (ICOA), Mohammedia, Morocco, April 2018.

[20] K. Daoudi and E. M. Boudi, "Genetic algorithm approach for spur gears design optimization," in Proceedings of the 2018 International Conference on Electronics, Control, Optimization and Computer Science (ICECOCS), Kenitra, Morocco, December 2018.

[21] S. B. Nandeppagoudar, "Design and numerical analysis of optimized planetary gear box," IOSR Journal of Mechanical and Civil Engineering, vol. 17, no. 3, pp. 5-11, 2017.

[22] N. Srinivas and K. Deb, "Multiobjective function optimization using nondominated sorting genetic algorithms," Evolutionary Computation, vol. 2, no. 3, pp. 221-248, 1995.

[23] D. W. Coit, "Genetic algorithms and engineering design," The Engineering Economist, vol. 43, no. 4, pp. 379-381, 1998. 
[24] E. Pennestrì, L. Mariti, P. P. Valentini, and V. H. Mucino, "Efficiency evaluation of gearboxes for parallel hybrid vehicles: theory and applications," Mechanism and Machine Theory, vol. 49, pp. 157-176, 2012.

[25] KHK, "Gear Technical Reference," Kohara Gear Ind. Co.,Ltd, Saitama, Japan.

[26] A. F. and J. Marsch, "Epicyclic gearing: a handbook," American Journal of Nursing, vol. 45, no. 4, p. 337, 2011.

[27] S. L. Qiao and Z. J. Han, "Optimization design of beam based on genetic algorithm," Advanced Materials Research, vol. 163-167, pp. 2365-2368, 2010.

[28] British Standard, Calculation of Load Capacity of Spur and Helical Gears, International Organization for Standardization, Geneva, Switzerland, 2006.

[29] E. Pennestri and P. P. Valentini, "A review of formulas for the mechanical efficiency analysis of two degrees-of-freedom epicyclic gear trains," Journal of Mechanical Design, vol. 125, no. 3, p. 602, 2003.

[30] J. Li and Q. Hu, "Power analysis and efficiency calculation of the complex and closed planetary gears transmission," Energy Procedia, vol. 100, pp. 423-433, 2016.

[31] L. P. Laus, H. Simas, and D. Martins, "Efficiency of gear trains determined using graph and screw theories," Mechanism and Machine Theory, vol. 52, pp. 296-325, 2012.

[32] D. R. Salgado and J. M. Del Castillo, "Analysis of the transmission ratio and efficiency ranges of the four-, five-, and six-link planetary gear trains," Mechanism and Machine Theory, vol. 73, pp. 218-243, 2014.

[33] J. M. Del Castillo, "The analytical expression of the efficiency of planetary gear trains," Mechanism and Machine Theory, vol. 37, no. 2, pp. 197-214, 2002.

[34] E. Pennestrí and P. P. Valentini, "Dynamic analysis of epicyclic gear trains by means of computer algebra," Multibody System Dynamics, vol. 7, no. 3, pp. 249-264, 2002. 


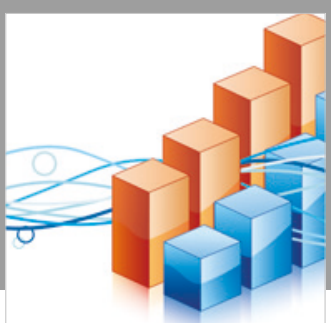

Advances in

Operations Research

\section{-n-m}
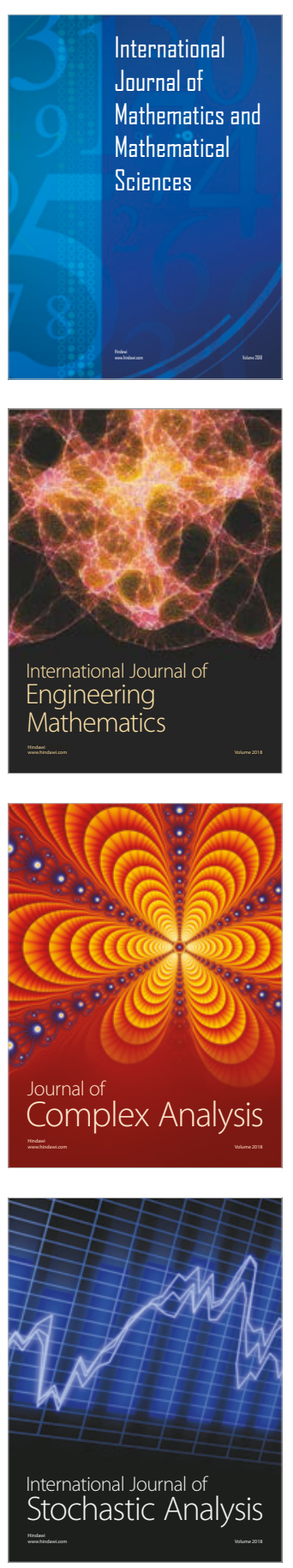
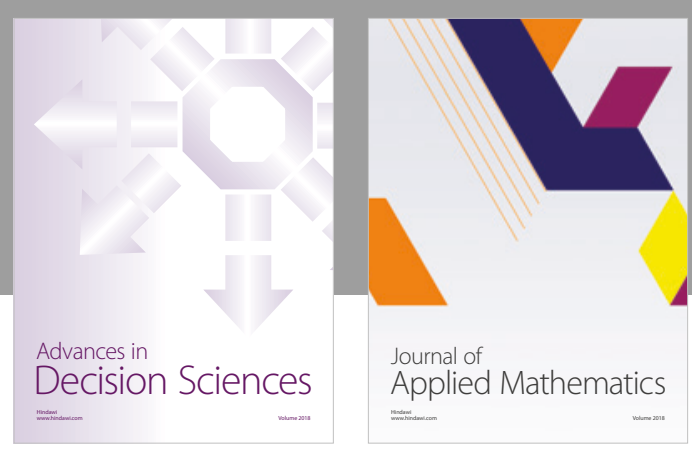

Journal of

Applied Mathematics
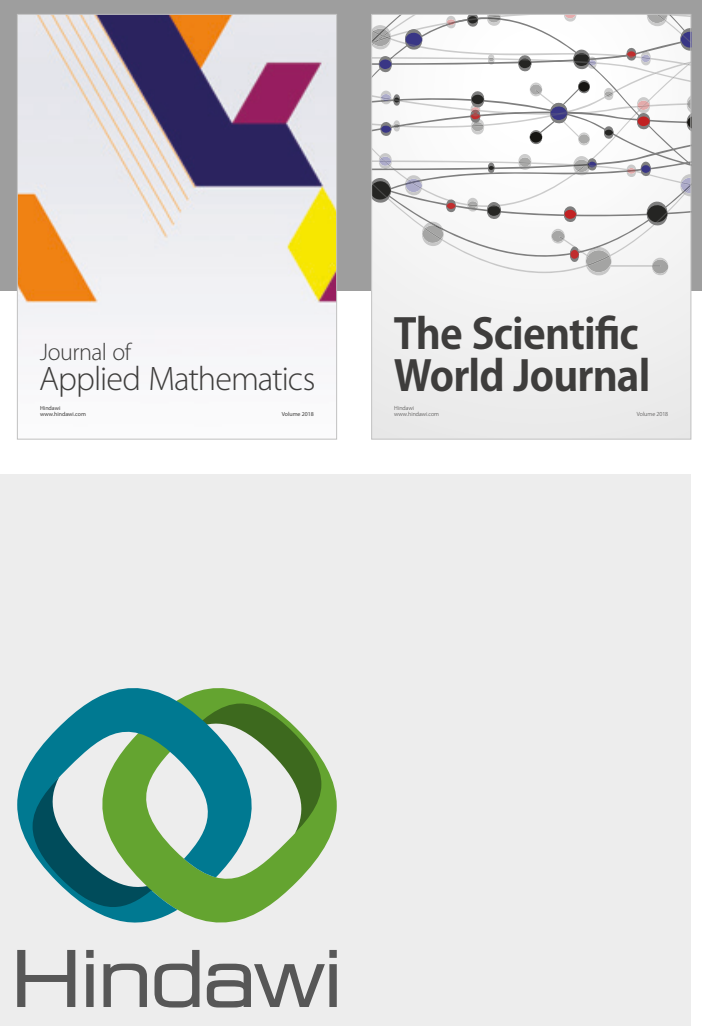

Submit your manuscripts at

www.hindawi.com

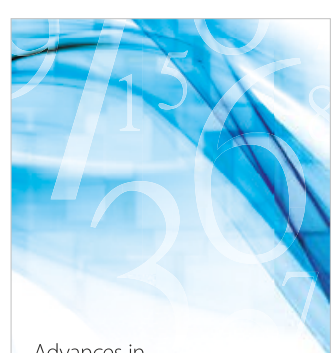

Advances in
Numerical Analysis
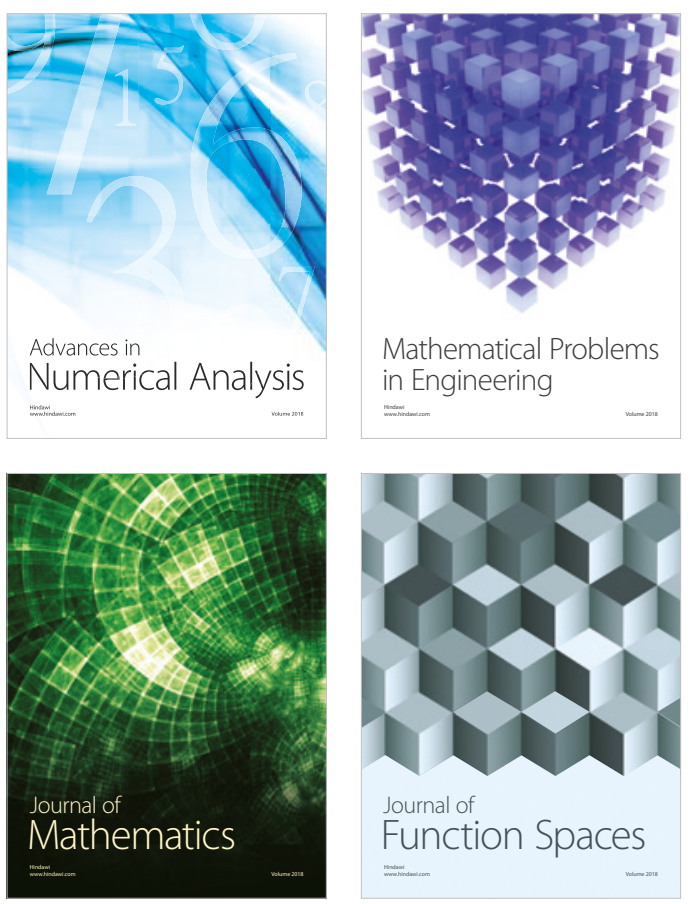

Mathematical Problems in Engineering

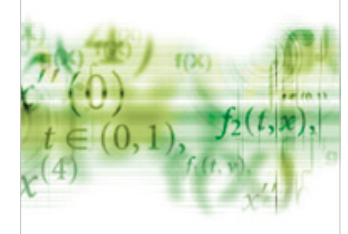

International Journal of

Differential Equations

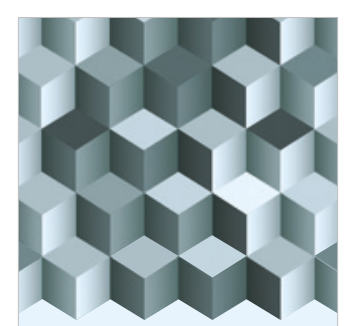

Journal of

Function Spaces

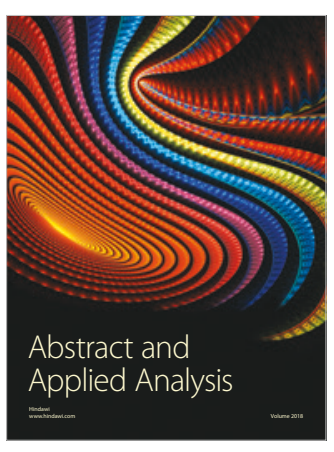

The Scientific

World Journal

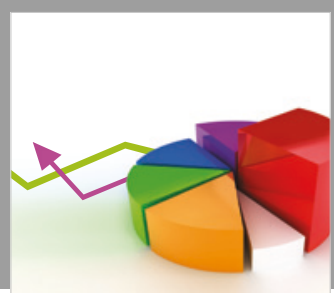

Journal of

Probability and Statistics
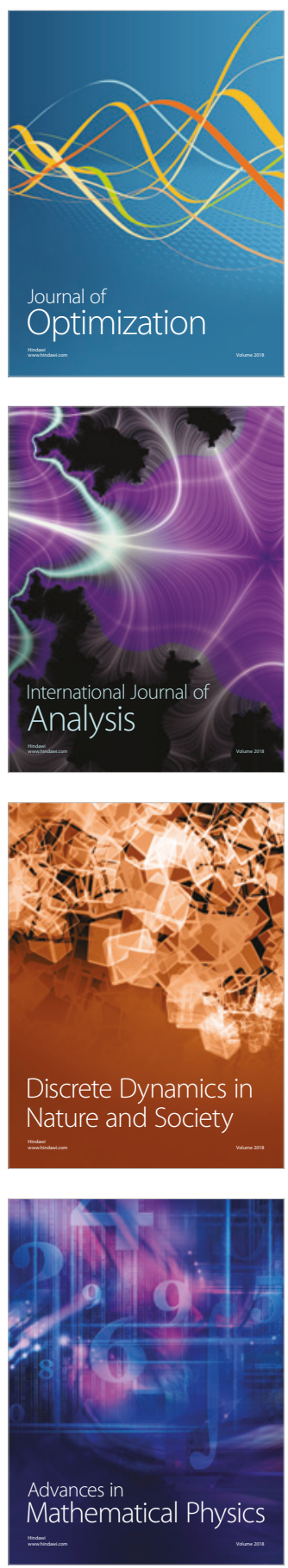